\title{
Emphysematous Osteomyelitis
}

\author{
Mark TP Mujer, ${ }^{1,2}$ Manoj P Rai, ${ }^{2}$ Mohamed Hassanein, ${ }^{3}$ Subhashis Mitra ${ }^{4}$
}

${ }^{1}$ Internal medicine, Michigan State University, Sparrow hospital, Lansing, Michigan, USA ${ }^{2}$ Michigan State University, Internal Medicine, Lansing, Michigan, USA

${ }^{3}$ Internal Medicine, Michigan State University College of Human Medicine, East Lansing, Michigan, USA

${ }^{4}$ Infectious disease, Michigan State University, Sparrow Hospital, Lansing, Michigan, USA

\section{Correspondence to} Dr Manoj P Rai,

manoj.rai@hc.msu.edu

Accepted 20 June 2018

\section{DESCRIPTION}

A 56-year-old man with a known history of type 2 diabetes mellitus, hypertension, nephrolithiasis and gout presented with fatigue and flank pain for 3 days. The above symptoms were associated with fevers and chills. On admission, the patient's vitals were remarkable for fever with maximum temperature $(\mathrm{T} \max ) 39.1^{\circ} \mathrm{C}$, hypotension requiring pressor support and tachycardia. On auscultation, he had reduced air entry at lung bases, distended abdomen, bipedal oedema and petechial rash over the upper extremities and the trunks. In addition, there was purplish discolouration over the left medial sacral area. Laboratory work-up was remarkable for elevated white cell count $21.4 \times 10^{9} / \mathrm{L}\left(4.0-12.0 \times 10^{9} / \mathrm{L}\right)$, creatinine $7.98 \mathrm{mg} / \mathrm{dL}(0.60-1.40 \mathrm{mg} / \mathrm{dL})$, anion gap of 25 , erythrocyte sedimentation rate of $70 \mathrm{~mm} /$ hour $(0-20 \mathrm{~mm} /$ hour $)$, total bilirubin of $4.9 \mathrm{mg} / \mathrm{dL}(0.2-1.2 \mathrm{mg} / \mathrm{dL})$ and lipase $422 \mathrm{U} / \mathrm{L}$ $(0-140 \mathrm{U} / \mathrm{L})$. Platelet count was $31 \times 10^{3} / \mu \mathrm{L}$ $\left(150-40010^{3} / \mu \mathrm{L}\right)$, aspartate aminotransferase of $71 \mathrm{U} / \mathrm{L}(10-40 \mathrm{U} / \mathrm{L})$ and alanine aminotransferase of $37 \mathrm{U} / \mathrm{L}$ (3-45 U/L). Septic shock was suspected, and the patient was placed on empiric coverage with piperacillin-tazobactam and vancomycin. His CT scan of the abdomen (figures 1 and 2) showed left emphysematous pyelonephritis and a $4 \mathrm{~mm}$ obstructing proximal left ureteral stone (figure 3). Urology was consulted, and the patient underwent cystoscopy with left ureteral stent placement. Interval CT abdomen and pelvis on the fourth day of antibiotic treatment showed resolution of air from the left pelvicalyceal system; however, it showed air bubbles within L5/S1 vertebral bodies and L5-S1 disc which

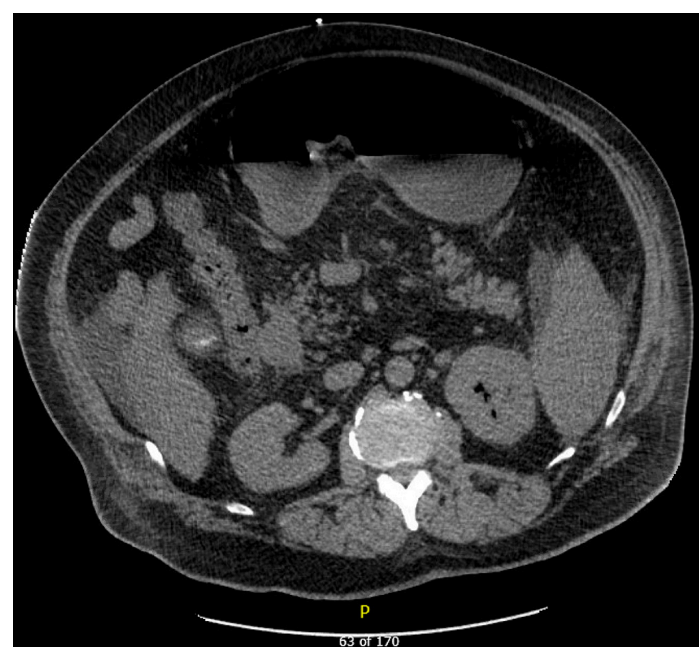

Figure 1 CT scan of the abdomen (axial section) showing left emphysematous pyelonephritis.

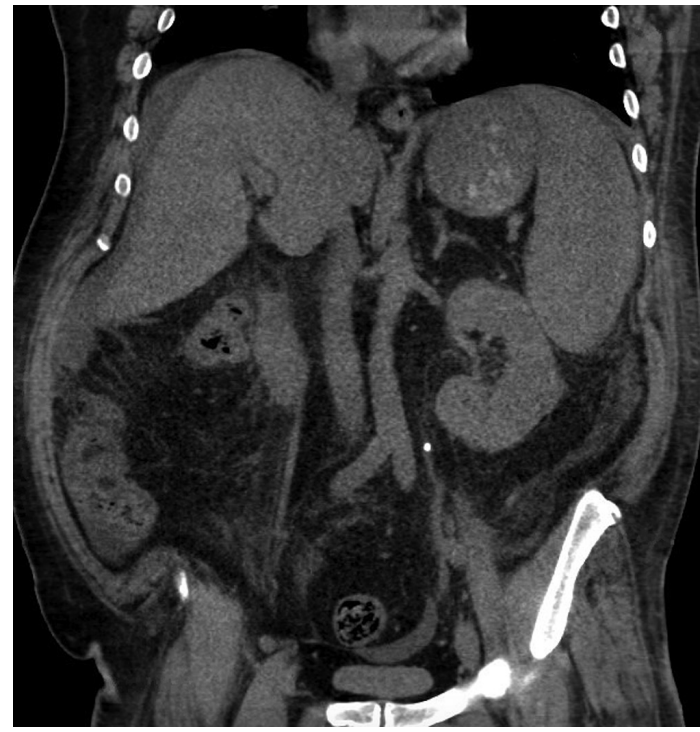

Figure 2 CT scan of the abdomen (coronal section) showing left emphysematous pyelonephritis.

was suggestive of emphysematous osteomyelitis (EO) (figures 4 and 5). The patient developed acute kidney injury, so antibiotics were switched to intravenous meropenem and linezolid. Blood cultures grew Escherichia coli (E. coli), linezolid (5 days) was then discontinued and meropenem (7 days) was then switched to ceftriaxone. Soon, he developed hives, it was attributed to ceftriaxone and was shifted to aztreonam which was renally dosed. Transoesophageal echo was performed since he had prolonged E. coli bacteraemia and was negative for vegetations. The blood cultures also cleared up, and he showed clinical improvement. He was subsequently discharged on aztreonam. A follow-up MRI of the back was recommended in 8 weeks.

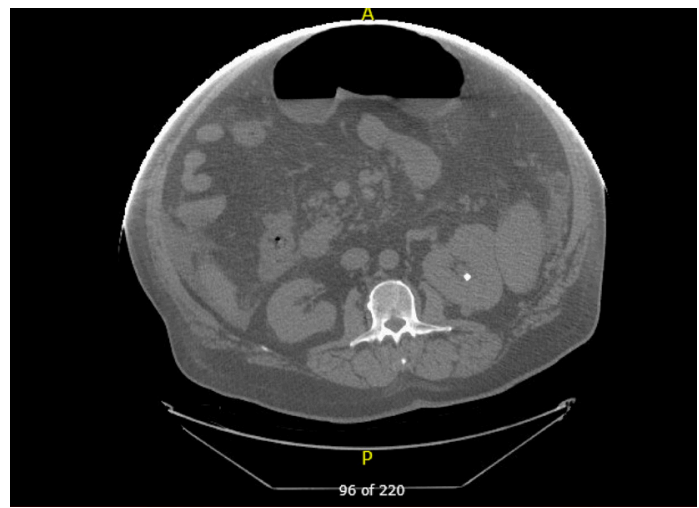

Figure 3 CT scan of the abdomen (axial section) showing a $4 \mathrm{~mm}$ obstructing proximal left ureteral stone. 


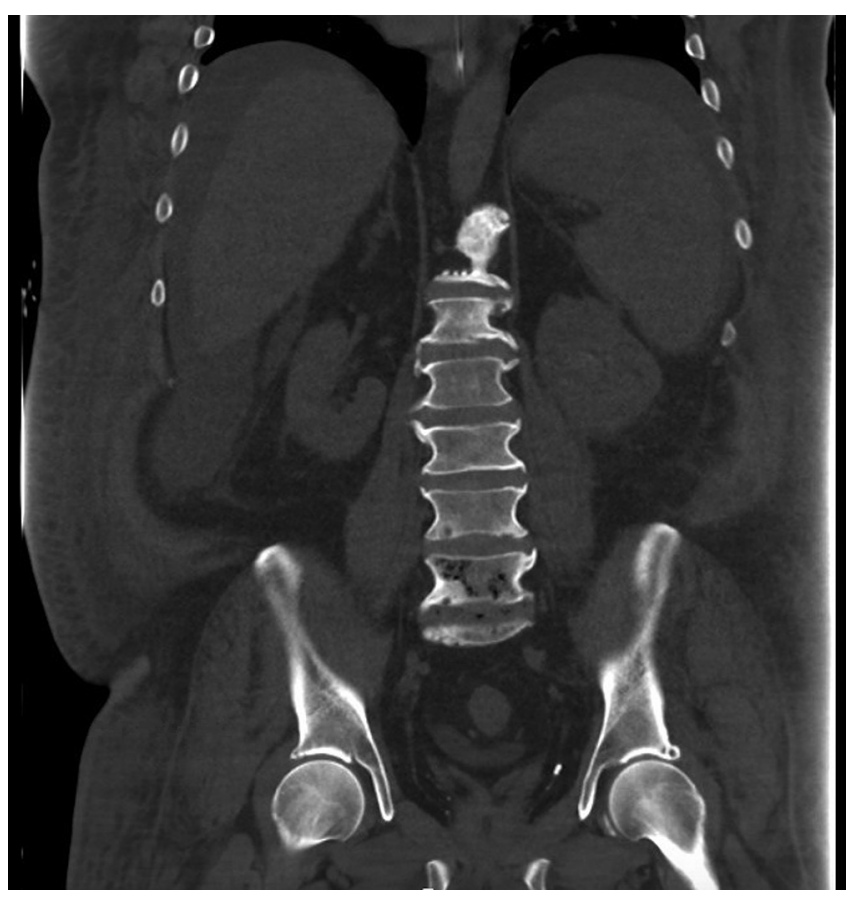

Figure 4 Interval CT abdomen and pelvis (coronal section) showing air within the $\mathrm{L} 5$ vertebral body, S1 vertebral body and L5-S1 disc space suggestive of emphysematous osteomyelitis.

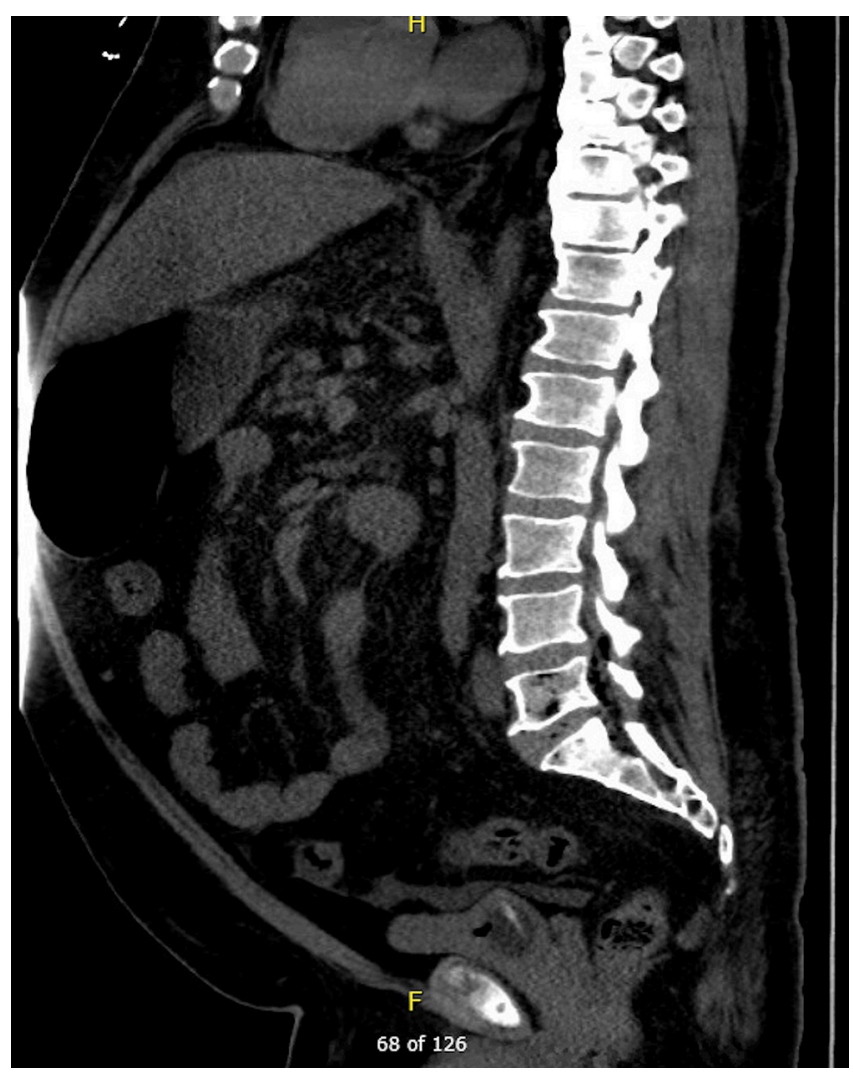

Figure 5 Interval CT abdomen and pelvis (sagittal section) showing air within the L5 vertebral body, S1 vertebral body and L5-S1 disc space suggestive of emphysematous osteomyelitis.
EO is a rare phenomenon. To date, only 30 cases have been reported in literature including our case. ${ }^{1-5}$ Intraosseous gas in the extra-axial skeleton is rare and pathognomonic for EO. ${ }^{1}$ The most commonly involved sites include vertebrae, pelvis, sacrum, femur, tibia, fibula and midfoot. ${ }^{1-5}$ The source of infection so far described to have caused EO are intra-abdominal and skin, ${ }^{5}$ in our case the source was suspected to be urinary tract infection which complicated with pyelonephritis. Diabetes mellitus and malignancy are the most common risk factors which have been known to predispose patients to EO. ${ }^{2}$ Members of the Enterobacteriaceae family or anaerobes (particularly Fusobacterium necrophorum) are the most common organisms causing EO. Various other organisms which have been described to have caused EO are Klebsiella pneumoniae, Enterobacter aerogenes, Clostridium spp, Staphylococcus aureus, non-haemolytic Streptococci and Enterococci, and Pseudomonas spp. ${ }^{1}$ Among the reported cases, E. coli has been the causative organism in nine cases (five monomicrobial (including our case) and four polymicrobial). ${ }^{1}$ EO has high morbidity and mortality, as high as $32 \%$ particularly in patients with diabetes mellitus so they should be treated aggressively with antibiotics to prevent possible bone necrosis and bone destruction. Surgery should be reserved for complications such as abscess formation or necrosis, and for those patients who do not respond to antimicrobial agents. EO should be treated with antimicrobial agents for a duration of 4-6 weeks similar to treatment of osteomyelitis.

\section{Learning points}

1. Intraosseous gas in the extra-axial skeleton should raise a high suspicion for emphysematous osteomyelitis (EO).

2. Surgical intervention is reserved for EO complicating with bone abscess, necrosis and for patients who fail on antimicrobial agents.

3. The high morbidity and mortality associated with EO warrants aggressive antibiotic treatment.

Contributors MM, MPR and MH wrote the case and description which includes learning points. SM revised the manuscript.

Funding The authors have not declared a specific grant for this research from any funding agency in the public, commercial or not-for-profit sectors.

Competing interests None declared.

Patient consent Obtained.

Provenance and peer review Not commissioned; externally peer reviewed.

\section{REFERENCES}

1 Lee J, Jeong $\mathrm{CH}$, Lee $\mathrm{MH}$, et al. Emphysematous Osteomyelitis due to Escherichia coli. Infect Chemother 2017;49:151-4.

2 Luey C, Tooley D, Briggs S, et al. Emphysematous osteomyelitis: a case report and review of the literature. Int J Infect Dis 2012;16:e216-e220.

3 Mautone M, Gray J, Naidoo P, et al. A case of emphysematous osteomyelitis of the midfoot: imaging findings and review of the literature. Case Rep Radiol 2014;2014:1-4

4 McDonnell 0, Khaleel Z. Emphysematous osteomyelitis. JAMA Neurol 2014;71:512.

5 Larsen J, Mühlbauer J, Wigger T, et al. Emphysematous osteomyelitis. Lancet Infect Dis 2015; 15:486. 
Copyright 2018 BMJ Publishing Group. All rights reserved. For permission to reuse any of this content visit http://group.bmj.com/group/rights-licensing/permissions.

BMJ Case Report Fellows may re-use this article for personal use and teaching without any further permission.

Become a Fellow of BMJ Case Reports today and you can:

- Submit as many cases as you like

- Enjoy fast sympathetic peer review and rapid publication of accepted articles

Access all the published articles

Re-use any of the published material for personal use and teaching without further permission

For information on Institutional Fellowships contact consortiasales@bmjgroup.com

Visit casereports.bmj.com for more articles like this and to become a Fellow 